\title{
Shisha Habit among Medical Students at College of Medicine and College of Dentistry-Baghdad University
}

\section{Hasan Khalaf Abed}

College of Medicine, University of Baghdad, Iraq

*Corresponding author: Hasan Khalaf Abed, College of Medicine, University of Baghdad, Iraq, Tel: + 964 7901352185; E-mail: dr_hasan_saidi@yahoo.com

Received date: November 08, 2017; Accepted date: November 20, 2017; Published date: November 25, 2017

Copyright: (c) 2017 Khalaf Abed H, et al. This is an open-access article distributed under the terms of the Creative Commons Attribution License, which permits unrestricted use, distribution, and reproduction in any medium, provided the original author and source are credited.

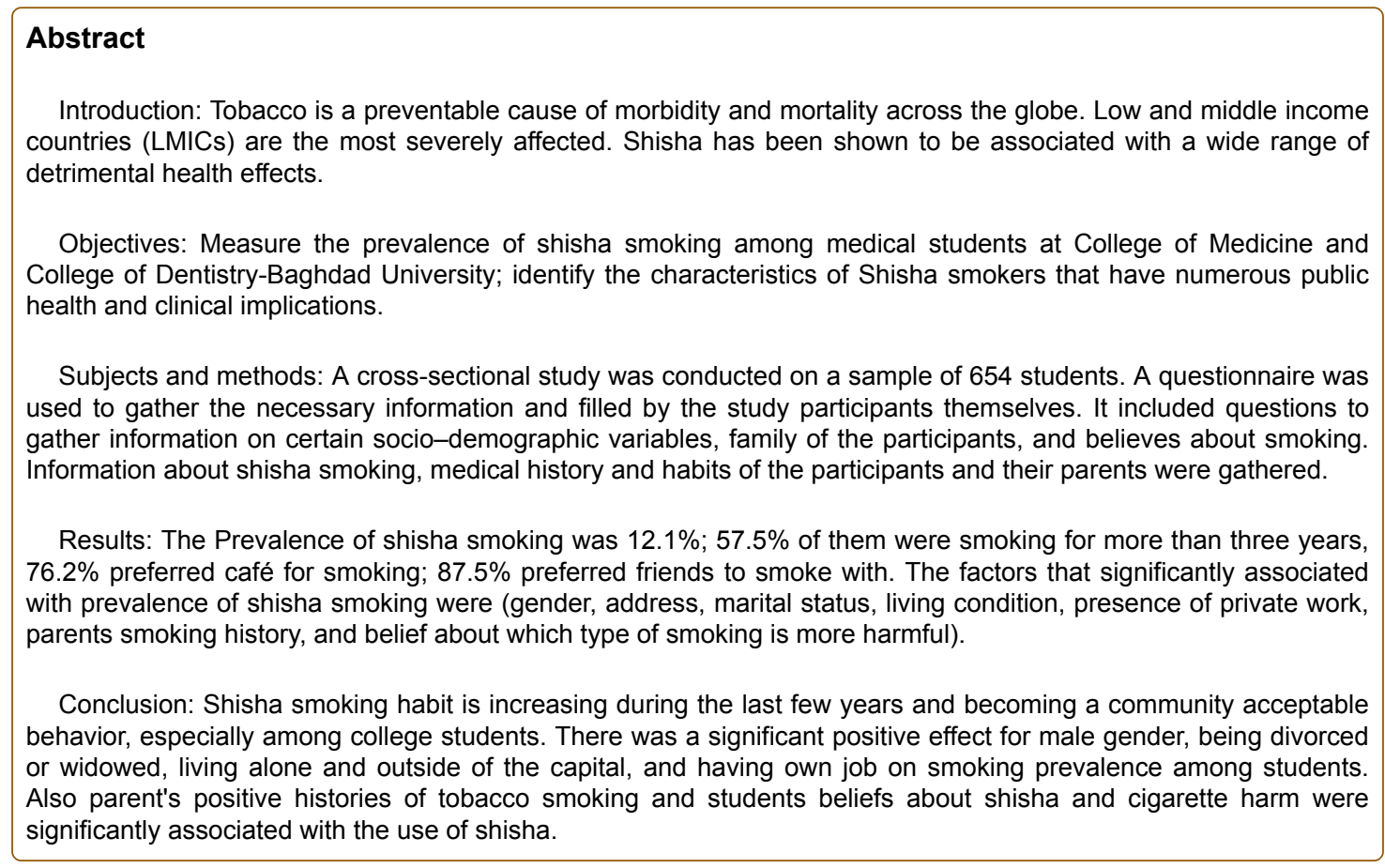

Keywords: Shisha habit; Smoking; Health effect

\section{Introduction and Literature Review}

Tobacco-attributable deaths are projected to double from 3.4 million to 6.8 million in Low and Middle Income Countries (LMICs), but to decline by $9 \%$ between 2002 and 2030 in High-Income Countries (HICs).

Shisha smoking is an ancient mode of tobacco use which has not posed any particular public health problem over the past centuries. It is a method of smoking tobacco invented by a physician named Hakim Abul-Fath Gilani in the 16th century. The purpose of the device was to pass smoke through water in an attempt to 'purify' the smoke, an unproven concept that has been repeatedly questioned by medical community.

It is known by many different names around the globe, with slight modifications as Hookah, Water-pipe, Narghile, Hubble-bubble, Nargeela, Argeela, Kalian, Ghelyoon, Ghalayan, Okka, Boury and Gouza.

As cigarette smoke, shisha contains many of the same toxicants including high concentrations of Carbon Monoxide (CO), nicotine, 'tar' and heavy metals. Nicotine content in shisha tobacco is documented to be $2-4 \%$, whereas in cigarettes, it is $1-3 \%$ [1]. Similarly, $\mathrm{CO}$ concentration in shisha smoke ranges from $0.34-0.40 \%$ compared to $0.41 \%$ in cigarette smoke.

Researches have focused on cigarettes, yet the increasing popularity of shisha has received much less attention. Shisha smoking has become to be fashionable and is widely used in Arabic worlds and even in Europe and in the United States. It has been claimed that 100 million people worldwide smoke shisha daily.

In some areas, shisha is more prevalent than cigarette smoking. There is less of a stigma associated with shisha than with cigarette smoking among Arab women in many countries, and therefore less of a gender differentiation [2]. Most of the epidemiologic studies of shisha use have been conducted among adults while a few reports have been published about university students.

Rising popularity of shisha use might occur due to several factors:

- Shisha is cheap and widely available.

- It considered as a social activity as it takes place at cafes, restaurants and parties.

- Many individuals cite socialization as a primary reason for their shisha use. 
Page 2 of 3

- Shisha is considered more pleasant by many smokers because the smell and taste.

In UK, the rise in consumption has likely been occurred due to the increase in the number of shisha cafes from 179 to 556 between 2007 and 2012 .

Absence of data on adolescent tobacco use in Iraq, led the Ministry of Health to conduct the Global Youth Tobacco Survey (GYTS) in Baghdad during 2008 [3]. GYTS is a school-based survey of students aged 13-15 years that is self-administered in classes in selected schools. Tobacco use in Iraq takes the form of cigarettes and shisha as in most Middle East countries [4]. Based on GYTS results, $7.4 \%$ of students aged 13-15 years reported having ever smoked cigarettes, $12.9 \%$ had ever smoked shisha, 3.2\% currently smoked cigarettes, and $6.3 \%$ currently smoked shisha [5]. Among never smokers aged 13-15 years, $13.0 \%$ reported they were likely to initiate cigarette smoking in the next year.

\section{Methods}

A cross-sectional study was conducted at the two medical colleges in Baghdad on 2017. Estimated sample size was 384, while we expanded it to 654 in order to increase the power of the study and overcome the non-responses [6]. A questionnaire was the tool for data collection.

\section{Ethical considerations}

Letter of Approval and facilitation were obtained from Baghdad College of Medicine and College of Dentistry. All participants were verbally informed about study objectives and methods and they were asked the permission to be part of the study [4]. All personal information was kept anonymous. Data were exclusively used for the sake of this study.

\section{Results}

Among the 654 students who completed their questionnaires; 342 participants from Medical College and 312 from College of Dentistry as shown in below Figure 1.

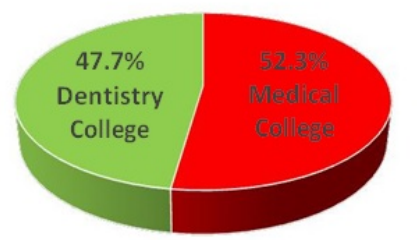

Figure 1: Participant from Medical College and College of Dentistry.

Participant's age ranged from 17 to 31 years with a mean of 20.6 years, the majorities of the participants were living with their families (91.4\%) and didn't have a private work rather than being students (93.7\%). The distribution of participants according to tobacco smoking was shown in below Figure 2.

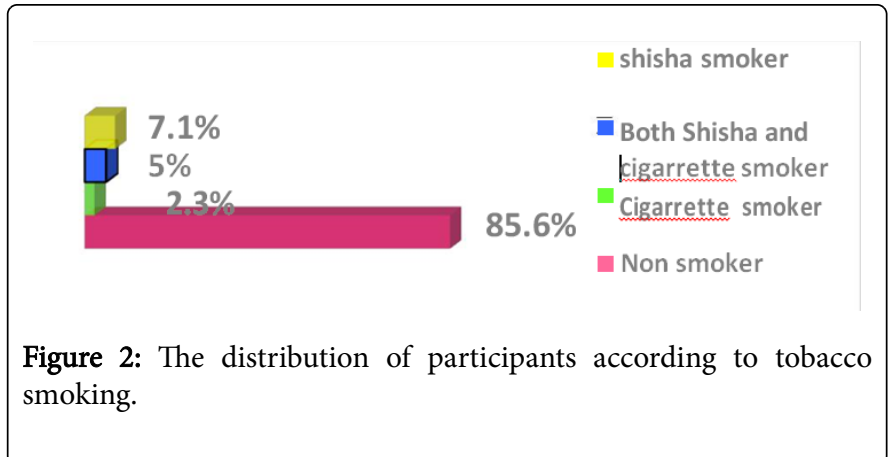

Highest proportions of parents of participants were non-smokers (74.8\% and $93.5 \%$ for fathers and mothers respectively).

We noticed the highest proportion of students whom are shisha smokers were smoking for more than three years (57.5\%), Also about half of them $(51.3 \%)$ smoke it on weekly basis and three quarters of them $(76.2 \%)$ preferred café as a place for shisha smoking [7]. We noticed most of shisha smokers preferred smoking at night $(73.8 \%)$, with/after eating (43.8\%) and when being with their friends (87.5\%).

Concerning time consumed for shisha smoking, the highest proportion spent around one hour per session (31.3\%) and most of them claimed the reason is to relieve stress $(32.5 \%)$ or to fulfill free timing (33.8\%).

It was noticed that $(25.7 \%)$ of shisha smokers considered it as a part of a prestigious and modern lifestyle while the majorities believed it is harmful for health (79.7\%).

From other hand it was noticed that the highest proportion of participants who were shisha smokers were males (29.4\%) with significant association $(\mathrm{P}=0.001)$, also they were among widowed or divorced participants (60\%), living alone (33.3\%) with significant association $(\mathrm{P}=0.003),(\mathrm{P}=0.004)$ respectively [8].

In the private work area, it was noticed a significant association $(\mathrm{P}=0.041)$ between shish smoking and having a private work in addition to being a student. Students whose Fathers and/or Mothers were smoking tobacco (cigarette and/or shisha) have significant association ( $\mathrm{P}=0.001)$ to be shisha smokers (32.8\%).

There was no significant association $(\mathrm{P}>0.05)$ between prevalence of shisha smoking and the following factors (crowding index, family monthly income, and stage of students).

\section{Discussion}

Students utilize and develop different tactics to deal with their stress, some are healthy and others not [9]. One of these unhealthy tactics is shisha smoking. This study result was higher than a result from a study of random sample in 2005 included 2298 students at Karbala University in Iraq which showed the prevalence of shisha smoking is $4.4 \%$, whilst the shisha smoking prevalence rate was $2 \%$ in the national survey in Iraq carried out in 2006.

The current result is comparable to that in the general California population as represented by the California Tobacco Survey; which is found that smoking prevalence in California population was $13-16 \%$ for those aged 18-40 years old.

Among students of a university in United States, the prevalence rates of shisha smoking was reported as $40.5 \%$. In a British university 
Citation: Khalaf Abed H (2017) Shisha Habit among Medical Students at College of Medicine and College of Dentistry-Baghdad University. J Health Educ Res Dev 5: 239. doi:10.4172/2380-5439.1000239

Page 3 of 3

prevalence of shisha smoking was found to be $38 \%$. A possible explanation for raising prevalence is the social acceptance. Also perception of less lethal and addicting than cigarette smoking.

Introduction of the modern society and less control of families over their youths and adolescents might enhance the likelihood of being influenced by friends [10-12].

Having plans to fill the student's leisure time through cultural and sports programs in university, and to teach some skills to cope with the temptation of shisha smoking in order to prevent students'

Tendency to this habit seems essential as a protective and preventive measure against shisha.

\section{Conclusion}

Shisha habit was increasing during the last few years and becoming a community acceptable behavior, especially among college students. There was a significant positive effect for male gender, being divorced or widowed, living alone, outside Baghdad, and having an own job on smoking prevalence among students, Parent's positive history of tobacco smoking and students beliefs about shisha and cigarette harm were significantly associated with the use of shisha.

\section{References}

1. Mathers C, Loncar D (2006) Projections of Global Mortality and Burden of Disease from 2002 to 2030. PLoS Medicine 3: e442.
2. Chaouachi K (2009) Hookah (Shisha, Narghile) Smoking and Environmental Tobacco Smoke (ETS). A Critical Review of the Relevant Literature and the Public Health Consequences. Int J Environ Res Public Health 6: 798-843.

3. Maziak W (2013) The waterpipe: An emerging global risk for cancer Cancer Epidemiol 37: 1-4.

4. Aljarrah K, Ababneh Z, Al-Delaimy W (2009) Perceptions of hookah smoking harmfulness: predictors and characteristics among current hookah users. Tobacco Induced Diseases 5: 16.

5. Knishkowy B (2005) Water-Pipe (Narghile) Smoking: An Emerging Health Risk Behavior. Pediatrics 116: e113-e119.

6. Sajid KM, Akhter M, Malik GQ (1993) Carbon monoxide fractions in cigarette and hookah (hubble bubble) smoke. J Pak Med Assoc 43: 179-182.

7. Radwan GN, Mohamed MK, El-Setouhy M, Israel E (2003) Review on water pipe smoking. J Egypt Soc Parasitol 33: 1051-1071.

8. Tamim H, Terro A, Kassem H, Ghazi A, Khamis T, et al. (2003) Tobacco use by university students, Lebanon, 2001. Addiction 98: 933-939.

9. Baddoura R, Wehbeh-Chidiac C (2001) Prevalence of tobacco use among the adult Lebanese population. East Mediterr Health J 7: 819-828.

10. Chaaya M, Awwad J, Campbell OM, Sibai A, Kaddour A (2003) Demographic and psychosocial profile of smoking among pregnant women in Lebanon: public health implications. Matern Child Health J 7: 179-186.

11. Mohammed HR, Zhang Y, Newman IM, Shell DF (2010) Waterpipe smoking in Kuwait. EMHJ, p: 16.

12. Jasim SM, Kadhim L, El-Awa F, Fouad H, Warren CW, et al. (2009) Tobacco use among students aged 13-15 years - Baghdad, Iraq, 2008. Morb Mortal Wkly Rep 58: 305-308. 